\title{
Predici as a polymer engineers' tool for the synthesis of polymers via anionic polymerization
}

\author{
Felix Kandelhard and Prokopios Georgopanos* \\ Helmholtz-Zentrum Hereon, Institute of Membrane Research, Max-Planck-Str. 1, \\ Geesthacht, 21502 Germany \\ E-mail: *prokopios.georgopanos@hereon.de \\ Phone: $+49(0) 4152$ 87-2420. Fax: $+49(0) 4152$ 87-2499
}




\section{Supporting Information}

\section{Nusselt-Correlation used in the calculation of the thermal transmit- tance}

The jacket-sided heat transfer coefficient was calculated from the respective Nusselt-number $\left(N u_{j}\right)$, which is correlated (Equation S1) to the Reynolds $\left(R e_{j}\right)$ - and Prandtl-number $\left(\operatorname{Pr}_{j}\right)^{1}$

$$
N u_{j}=\frac{0.03 \cdot R e_{j}^{0.75} \cdot \operatorname{Pr}_{j}}{1+\frac{1.74 \cdot\left(\operatorname{Pr}_{j}-1\right)}{R e_{j}^{0.125}}}
$$

Depending on the type of stirrer installed inside the reactor one of the following correlations was used for the reactor-sided Nusselt-number $\left(N u_{R}\right)$. All equations contain the Reynolds-number inside the reactor $\left(R e_{R}\right)$ as well as the Prandtl-number of the reaction medium $\left(\operatorname{Pr}_{R}\right)$.

\section{Inclined Blade Stirrer:}

$$
N u_{R}=A \cdot \operatorname{Re}_{R}^{\frac{2}{3}} \cdot \operatorname{Pr}_{R}^{\frac{1}{3}}
$$

with:

$$
A=0.54 \cdot\left(\frac{d_{\text {Stirrer }}}{d_{\text {Reactor }}}\right)^{-0.25} \cdot\left(\frac{h_{\text {Stirrer }}}{d_{\text {Reactor }}}\right)^{0.15} \cdot\left(\frac{h_{\text {Stirrer }}}{h_{\text {Liquid }}}\right)^{0.15} \cdot \sin (\phi)
$$

In Equation S3 are: $d_{\text {Stirrer }}$ the diameter of the stirrer $[\mathrm{m}], d_{\text {Reactor }}$ : the diameter of the reactor $[\mathrm{m}], h_{\text {Stirrer }}$ : the height of the individual stirrer blades, $[\mathrm{m}], h_{\text {Liquid }}$ the height of the liquid (reaction medium) inside the reactor $[\mathrm{m}]$, and $\phi$ the angle of the stirrer blades $[\mathrm{rad}]$. 


\section{Anchor Agitator:}

Heating:

$$
N u_{R}=0.242 \cdot\left(R e_{R} \cdot \operatorname{Pr}_{R}^{\frac{1}{2}}+4000\right)^{\frac{2}{3}}
$$

Cooling:

$$
N u_{R}=0.358 \cdot\left(R e_{R} \cdot \operatorname{Pr}_{R}^{\frac{1}{2}}+4000\right)^{\frac{2}{3}}
$$

Paravisc $(\mathrm{A}=0.49)$ and Spiral Stirrer $(\mathrm{A}=0.45)$ :

$$
N u_{R}=A \cdot R e_{R}^{\frac{2}{3}} \cdot \operatorname{Pr}_{R}^{\frac{1}{3}}
$$

\section{Reactor and Stirrer Geometries}

In the simulations glass reactors with varying sizes between $0.5 \mathrm{~L}$ and $15.0 \mathrm{~L}$ are used. The geometrical data of the reactors are based on those of the Polyclave $(0.5 \mathrm{~L}, 1.0 \mathrm{~L}, 2.0 \mathrm{~L}$, and 5.0 L) and Kiloclave (15.0 L) series from Büchi (Büchi AG, Uster, Switzerland). These data including the inner reactor diameter $\left(d_{R}\right)$, the reactor height $\left(h_{R}\right)$, the diameter of the jacket inlet $d_{j, \text { Inlet }}$, the diameter of the jacket $\left(d_{j}\right)$, the radius of the rounded reactor floor $r_{c y c l i c}$, and the diameter of the spiral stirrer $\left(d_{\text {Stirrer }}\right)$ are summarized in Table S1.

In case of the $0.5 \mathrm{~L}$ reactor the stirrer type and sizes were varied to estimate their influence on the heat transfer behavior of the reaction system. In addition to the spiral stirrer with a diameter of $40 \mathrm{~mm}$ a Paravisc stirrer with a diameter of $68 \mathrm{~mm}$, an anchor stirrer with a diameter of $68 \mathrm{~mm}$, as well as an inclined blade stirrer with four blades and a diameter of $40 \mathrm{~mm}$ were tested. 
Table S1: Geometric data of the reactors used in the simulations including he inner reactor diameter $\left(d_{R}\right)$, the reactor height $\left(h_{R}\right)$, the diameter of the jacket inlet $d_{j, \text { Inlet }}$, the diameter of the jacket $\left(d_{j}\right)$, the radius of the rounded reactor floor $r_{c y c l i c}$, and the diameter of the spiral stirrer $\left(d_{\text {Stirrer }}\right)$

\begin{tabular}{llllll}
\hline Lenghts [mm] & $0.5 \mathrm{~L}$ & $1.0 \mathrm{~L}$ & $2.0 \mathrm{~L}$ & $5.0 \mathrm{~L}$ & $15.0 \mathrm{~L}$ \\
\hline$d_{R}$ & 72 & 82 & 112 & 112 & 240 \\
$h_{R}$ & 124 & 195 & 250 & 555 & 420 \\
$d_{j, \text { Inlet }}$ & 16 & 16 & 16 & 16 & 26 \\
$d_{j}$ & 14 & 14 & 14 & 14 & 24 \\
$r_{\text {cyclic }}$ & 27 & 42 & 56 & 123 & 20 \\
$d_{\text {Stirrer }}$ & 40 & 68 & 93 & 93 & 115 \\
\hline
\end{tabular}

\section{Copolymerization Model}

The kinetic model was extended to a copolymerization model including isoprene $(I p)$ as the second monomer besides styrene $(S t)$. The model contains all possible homo- and copolymerization steps as well as the initiation reactions between sec-BuLi $(s-B u L i)$ and both monomers. Depending on the polymerization process (e.g. block copolymerization), individual reaction steps may not occur. A second living polymeric species was included in the model representing the polymer chain with an isoprene unit as the living end $\left(P_{1, i}^{*}\right)$ extending the model to a total of three polymeric species. The other two are the styrene-ended $\left(P_{n+1, s}^{*}\right)$ and the deactivated polymer chain $\left(P_{n}^{\text {dead }}\right)$.

$$
\begin{gathered}
s-B u L i+I p \stackrel{k_{i}}{\longrightarrow} P_{1, i}^{*} \\
s-B u L i+S t \stackrel{k_{i}}{\longrightarrow} P_{1, s}^{*} \\
P_{n, s}^{*}+S t \stackrel{k_{p, s s}}{\longrightarrow} P_{n+1, s}^{*} \\
P_{n, i}^{*}+I p \stackrel{k_{p, i i}}{\longrightarrow} P_{n+1, i}^{*} \\
P_{n, i}^{*}+S t \stackrel{k_{p, i s}}{\longrightarrow} P_{n+1, s}^{*} \\
P_{n, s}^{*}+I p \stackrel{k_{p, s i}}{\longrightarrow} P_{n+1, i}^{*}
\end{gathered}
$$




$$
P_{n, s}^{*} \stackrel{k_{t}}{\longrightarrow} P_{n}^{\text {dead }}
$$

As for the homopolymerization step of styrene $\left(k_{p, s s, e f f}\right)$, the copolymerization propagation rate coefficients are modified to describe the formation of aggregates and their influence on the polymerization rate. These are the propagation rate coefficient describing the addition of an isoprene monomer to either an isoprene-ended $\left(k_{p, i i, e f f}\right)$ or styrene-ended chain $\left(k_{p, s i, e f f}\right)$ as well as the addition of a styrene unit to an isoprene-ended chain $\left(k_{p, i s, e f f}\right)$. While polymer chains with styrene anions form dimers, isoprene anions exist mainly as tetramers.

$$
\begin{aligned}
& k_{p, s s, e f f}=\frac{k_{p, s s}}{\left[P_{n, s}^{*}\right]^{\frac{1}{2}}} \\
& k_{p, i i, e f f}=\frac{k_{p, i i}}{\left[P_{n, i}^{*}\right]^{\frac{3}{4}}} \\
& k_{p, i s, e f f}=\frac{k_{p, i s}}{\left[P_{n, i}^{*}\right]^{\frac{3}{4}}} \\
& k_{p, s i, e f f}=\frac{k_{p, s i}}{\left[P_{n, s}^{*}\right]^{\frac{1}{2}}}
\end{aligned}
$$

The propagation rate coefficient of the homopolymerization of isoprene $\left(k_{p, i i}\right)$, as well as the copolymerization between isoprene and styrene $\left(k_{p, s i}\right.$ and $\left.k_{p, i s}\right)$, are taken from the literature and summarized in Table S2.

Table S2: Propagation rate coefficient of isoprene and the copolymerization between isoprene and styrene The constants are written in form of temperature-dependent Arrhenius parameters with the frequency factor $\left(A_{f}\right)$ and the activation energy divided by the universal gas constants $\left(\frac{E_{a}}{R}\right)$

\begin{tabular}{lll}
\hline Rate Coefficient $^{2}$ & $A_{f}[$ different units] & $\frac{E_{a}}{R}[\mathrm{~K}]$ \\
\hline$k_{p, i i}$ & $2.30 \cdot 10^{11}\left[\mathrm{~L}^{0.25} \mathrm{~mol}^{-0.25} \mathrm{~s}^{-1}\right]$ & $9.93 \cdot 10^{3}$ \\
$k_{p, s i}$ & $4.62 \cdot 10^{7}\left[\mathrm{~L}^{0.5} \mathrm{~mol}^{-0.5} \mathrm{~s}^{-1}\right]$ & $5.50 \cdot 10^{3}$ \\
$k_{p, i s}$ & $2.87 \cdot 10^{10}\left[\mathrm{~L}^{0.25} \mathrm{~mol}^{-0.25} \mathrm{~s}^{-1}\right]$ & $10.00 \cdot 10^{4}$ \\
\hline
\end{tabular}




\section{Physical Properties of Substances}

\section{Physical Properties of the Thermofluid Malotherm XC}

The thermo-oil Marlotherm XC was chosen as the thermo-fluid in the reactor jacket for all reactions carried out because of its wide temperature range. The physical parameters necessary for the calculation of the heat transfer properties were taken from the product data-sheet and fitted as temperature $(T)$ dependent function in the range from $-90{ }^{\circ} \mathrm{C}$ to $270{ }^{\circ} \mathrm{C}$. The density $(\rho)$, specific heat capacity $\left(c_{p}\right)$, thermal conductivity $(\lambda)$, and dynamic viscosity $(\eta)$ functions are shown in Equation S18 to S21. ${ }^{3}$

$$
\begin{gathered}
\rho\left[\mathrm{kg} \cdot \mathrm{m}^{-3}\right]=1118.65-1.15 \cdot T+1.68 \cdot 10^{-3} \cdot T^{2} \\
-2.51 \cdot 10^{-6} \cdot T^{3}+1.97 \cdot 10^{-10} \cdot T^{4} \\
c_{p}\left[\mathrm{~J} \cdot \mathrm{kg}^{-1} \cdot \mathrm{K}^{-1}\right]=530.81+9.81 \cdot \mathrm{T}-2.62 \cdot 10^{-2} \cdot T^{2} \\
+2.57 \cdot 10^{-5} \cdot T^{3}+5.07 \cdot 10^{-9} \cdot T^{4} \\
\lambda\left[\mathrm{W} \cdot \mathrm{m}^{-1} \mathrm{~K}^{-1}\right]=0.20-2.28 \cdot 10^{-4} \cdot T \\
\eta\left[\mathrm{Pa} \cdot \mathrm{s}^{-1}\right]=2.42 \cdot 10^{-6} \cdot e^{\frac{12375.10}{R \cdot T}}
\end{gathered}
$$

In Equation S21 is $R$ the universal gas constant.

\section{Physical Properties of the Reaction Mixture}

The physical properties of the substances involved in the reaction are taken from the literature (the respective references are given in the substance sections) and fitted as temperaturedependent functions summarized in the equations: 


\section{Styrene}

The data is taken from the literature. ${ }^{4}$

$$
\begin{gathered}
\rho\left[\mathrm{kg} \cdot \mathrm{m}^{-3}\right]=1206.70-1.03 \cdot T \\
c_{p}\left[\mathrm{~J} \cdot \mathrm{kg}^{-1} \cdot \mathrm{K}^{-1}\right]=799.30+3.22 \cdot T \\
\lambda\left[\mathrm{W} \cdot \mathrm{m}^{-1} \mathrm{~K}^{-1}\right]=0.20+2.00 \cdot 10^{-4} \cdot T \\
\eta\left[\mathrm{Pa} \cdot \mathrm{s}^{-1}\right]=4.09 \cdot 10^{-3} \cdot e^{0.013 \cdot T}
\end{gathered}
$$

\section{Cyclohexane}

The data is taken from the literature. ${ }^{5}$

$$
\begin{gathered}
\rho\left[\mathrm{kg} \cdot \mathrm{m}^{-3}\right]=1168.30-1.29 \cdot T \\
c_{p}\left[\mathrm{~J} \cdot \mathrm{kg}^{-1} \cdot \mathrm{K}^{-1}\right]=497.34+4.01 \cdot T \\
\lambda\left[\mathrm{W} \cdot \mathrm{m}^{-1} \mathrm{~K}^{-1}\right]=0.19+2.00 \cdot 10^{-4} \cdot T \\
\eta\left[\mathrm{Pa} \cdot \mathrm{s}^{-1}\right]=1.97 \cdot 10^{-3} \cdot e^{0.0011 \cdot T}
\end{gathered}
$$

\section{Isoprene}

The density, and heat capacity ${ }^{6}$ as well as thermal conductivity, and viscosity data ${ }^{7}$ are taken from the literature.

$$
\begin{gathered}
\rho\left[\mathrm{kg} \cdot \mathrm{m}^{-3}\right]=0.800-1.49 \cdot 10^{-4} \cdot T-1.52 \cdot 10^{-6} \cdot T^{2} \\
c_{p}\left[\mathrm{~J} \cdot \mathrm{kg}^{-1} \cdot \mathrm{K}^{-1}\right]=428.00-0.76 \cdot T+3.32 \cdot 10^{-3} \cdot T^{2} \\
\lambda\left[\mathrm{W} \cdot \mathrm{m}^{-1} \mathrm{~K}^{-1}\right]=0.24+4.00 \cdot 10^{-4} \cdot T
\end{gathered}
$$




$$
\eta\left[\mathrm{Pa} \cdot \mathrm{s}^{-1}\right]=4.48 \cdot 10^{-3} \cdot e^{0.011 \cdot T}
$$

The heat of polymerization of isoprene was set to $-71 \mathrm{~kJ} \mathrm{~mol}{ }^{-1}{ }^{8}$

\section{Polystyrene}

The density ${ }^{9}$ and heat capacity ${ }^{10}$ are taken from the literature. Have to be changed

$$
\begin{gathered}
\rho\left[\mathrm{kg} \cdot \mathrm{m}^{-3}\right]=1250-0.605 \cdot T \\
c_{p}\left[\mathrm{~J} \cdot \mathrm{kg}^{-1} \cdot \mathrm{K}^{-1}\right]=108-42+4.28 \cdot(T-273.15 K)
\end{gathered}
$$

\section{Polyisoprene}

The density, and heat capacity $^{6}$ are taken from the literature.

$$
\begin{gathered}
\rho\left[\mathrm{kg} \cdot \mathrm{m}^{-3}\right]=906 \\
c_{p}\left[\mathrm{~J} \cdot \mathrm{kg}^{-1} \cdot \mathrm{K}^{-1}\right]=163.18+4.64 \cdot T
\end{gathered}
$$

\section{Viscosity of the Polymer Solution}

The properties of the reaction mixture were calculated as the average value weighted by the mass fraction of the substances. In the case of the viscosity, the molar ratios were used instead to calculate the mean viscosity of all low molecular weight components. ${ }^{11}$ This value was then used as the base viscosity $\left(\eta_{\text {solvent }}\right)$ combined with the Mark-Houwink parameters to compute the viscosity of the polymer solution $\left(\eta_{\text {Solvent }}\right)$.

$$
\begin{gathered}
\eta_{\text {Solution }}=\eta_{\text {Solvent }} \cdot\left([\eta] \cdot \beta_{\text {Polymer }}+k_{H} \cdot[\eta]^{2} \cdot \beta_{\text {Polymer }}\right) \\
{[\eta]=K_{M H} \cdot\left(\bar{M}_{w}\right)^{a}}
\end{gathered}
$$


In Equation S38 are: $[\eta]$ the intrinsic viscosity, $\beta_{\text {Polymer }}$ the mass concentration of the polymer in the solution, and $k_{H}\left(0.5 \mathrm{~kg} \cdot \mathrm{L}^{-1}\right)$ the Huggins coefficient. In Equation S39 are: $\bar{M}_{w}$ the weight-average molecular weight, $\alpha(0.5)$ and $K_{M H}\left(8.8 \cdot 10^{-1} \mathrm{~L} \cdot \mathrm{kg}^{-1}\right)$ the Mark-Houwink parameters. ${ }^{8}$ Figure S1 shows the viscosity profiles of the set of simulations carried out with varying temperature and monomer contents.

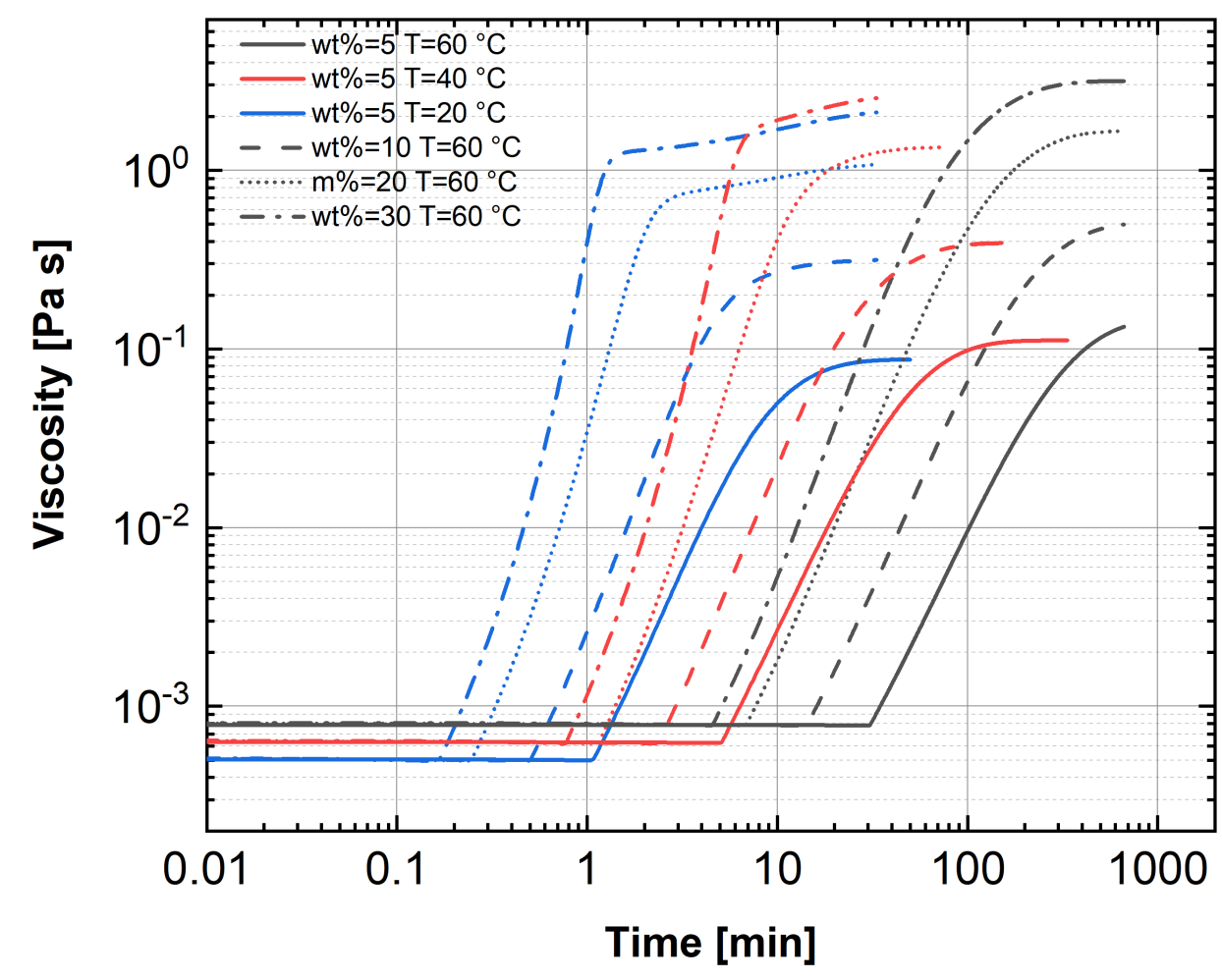

Figure S1: Simulated viscosity profiles for varying monomer content ( $5 \mathrm{wt} \%$ : straight lines, $10 \mathrm{wt} \%$ : dashed lines, $20 \mathrm{wt} \%$ dotted lines, and $30 \mathrm{wt} \%$ : dashed/dotted lines) and starting temperature $\left(20{ }^{\circ} \mathrm{C}\right.$ : black, $40{ }^{\circ} \mathrm{C}$ : red, and $60{ }^{\circ} \mathrm{C}$ : blue $)$ 


\section{Heat Capacity of the Reactors}

The heat capacity of the reactors are estimated from the specific heat capacity of the material borosilicate glass $3.3\left(830 \mathrm{~J} \mathrm{~kg}^{-1} \mathrm{~K}^{-1}\right)$ and its assumed weight. The mass of all walls as well as the stirrer was estimated from there volume and density (Table S3).

Table S3: Estimated mass and heat capacity of the different reactors including the stirrer

\begin{tabular}{lll}
\hline Reactor Volume & Mass $[\mathrm{kg}]$ & Heat Capacity $\left[\mathrm{J} \mathrm{K}^{-1}\right]$ \\
\hline $0.5 \mathrm{~L}$ & 0.187 & 155 \\
$1.0 \mathrm{~L}$ & 0.321 & 266 \\
$2.0 \mathrm{~L}$ & 0.479 & 398 \\
$5.0 \mathrm{~L}$ & 1.108 & 920 \\
$15.0 \mathrm{~L}$ & 5.940 & 4930 \\
\hline
\end{tabular}

\section{Pressure Calculation}

Anionic polymerizations are carried out under a protective gas atmosphere. These gases are mostly nitrogen or argon. The pressure of the non condensable material in the reactor $p_{0}$ (Eq. S40) is calculated with the ideal gas law and is also increasing with the temperature. It is assumed that the reaction is started with a standard pressure of $101325 \mathrm{~Pa}$ at $20{ }^{\circ} \mathrm{C}$.

$$
p_{0}(T)=101325.00 \mathrm{~Pa}+345.64 \mathrm{~Pa} \cdot \mathrm{K}^{-1} \cdot(T(t)-293.15 \mathrm{~K})
$$

The partial pressures of the different components are calculated by the Antoine equation $\left(\ln \left(p_{i}\right)=A-\frac{B}{C+T}\right)$. The used parameters are shown in Table S4.

Table S4: Parameters for the Antoine equation for the computation of the partial pressures of the substances in the reaction mixture

\begin{tabular}{llrl}
\hline Substance & $\mathrm{A}$ & $\mathrm{B}$ & $\mathrm{C}$ \\
\hline Styrene $^{12}$ & 4.22 & 1525.06 & -56.38 \\
Isoprene $^{13}$ & 3.22 & 706.92 & -87.05 \\
Cyclohexane $^{14}$ & 4.14 & 1316.55 & -56.38 \\
\hline
\end{tabular}




\section{Equations used in the evaluation of the simulation results}

\section{Runaway Evaluation}

The adiabatic temperature rise $\left(T_{a d}\right)$ is calculated (Equation S41) from the product of the

amount of monomer $\left(n_{\text {mono }}\right)$ and the molar heat of polymerization $\left(\Delta H_{p}\right)$ divided by the the total heat capacity $\left(C_{p}\right)$. The total heat capacity is formed from the individual contributions of the reaction mixture and the reactor built-in components (e.g. stirrer).

$$
T_{a d}=\frac{n_{\text {mono }} \cdot \Delta H_{p}}{C_{p}}
$$

The dimensionless temperature $(\theta)$ is calculated (Equation S42) from the activation energy of the propagation step $\left(E_{a}\right)$, the universal gas constant $(R)$, the jacket temperature $\left(T_{j}\right)$, and the temperature of the reaction mixture $\left(T_{R}\right)$.

$$
\theta=\frac{E_{a}}{R \cdot T_{j}} \frac{T_{R}-T_{j}}{T_{j}}
$$

\section{Heat Introduced by the Stirrer}

The heat flow introduced by the stirrer $P$ can be calculated using the Newton number $N e$ (Equation S43). With the density $\rho$, the diameter of the stirrer $d_{\text {Stirrer }}$, and the stirrer speed $n_{\text {Stirrer }}$.

$$
P=N e \cdot \rho \cdot n_{\text {Stirrer }}^{3} \cdot d_{\text {Stirrer }}^{5}
$$

The Newton can be calculated from the Reynolds Number using an empiric correlation (Equation S44) The coefficients $C_{l}$ and $C_{t}$ depend on the stirrer type and taken from the literature. $^{1}$

$$
N e=\left[\left(\frac{C_{l}}{R e}\right)^{2}+\left(\frac{C_{t}}{(10+R e)^{\frac{1}{4}}}\right)^{2}\right]^{\frac{1}{2}}
$$

These equations were applied for the simulations with $10 \mathrm{wt} \%$ carried out at $60{ }^{\circ} \mathrm{C}$ in the $1 \mathrm{~L}, 5 \mathrm{~L}$ and $15 \mathrm{~L}$ reactor as well as the reaction with $30 \mathrm{wt} \%$ carried out at $60{ }^{\circ} \mathrm{C}$ in the 
$0.5 \mathrm{~L}$ reactor. The coefficients for a spiral stirrer are: $C_{l}=315$ and $C_{t}=4.3 .{ }^{1}$ The results are shown in Figure S2.

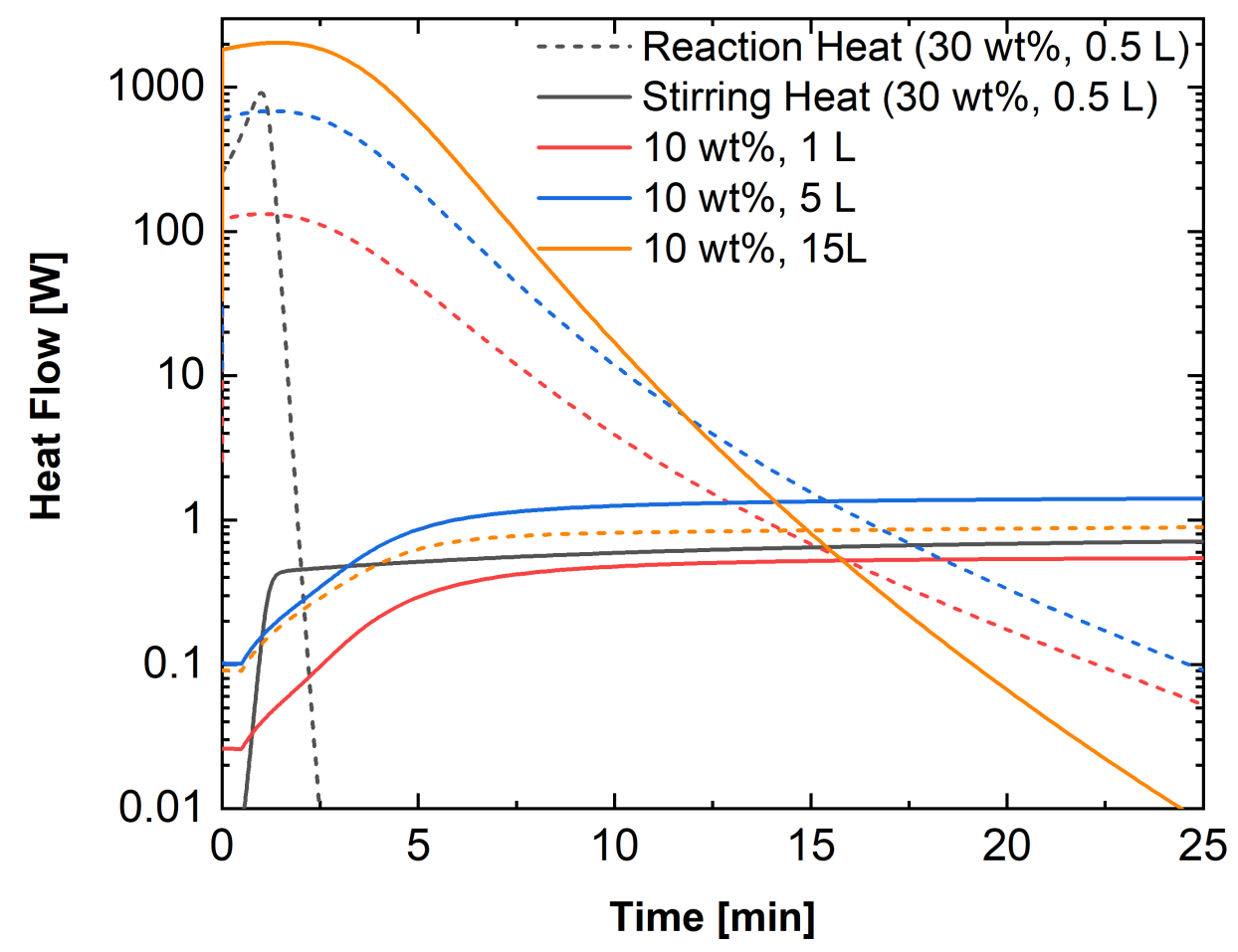

Figure S2: Reaction heat (dashed lines) and heat introduced by the stirrer (straight lines) for different simulation setups. 


\section{Scale Up}

\section{Evaluation of the Simulation Results}

The simulation results were evaluated in terms of conversion and product properties. These values in form of the time after conversion of 0.95 are reached $\left(t_{0.95}\right.$, given in decimal minutes) and the number average mass at this point $\left(\bar{M}_{n, 0.95}\right)$ are summarized in Table S5. It also contains the maximum temperature $\left(T_{\max }\right)$ reached.

Table S5: Simulated time with 0.95 conversion $\left(t_{0.95}\right)$, the number average molecular mass $\left(\bar{M}_{n, 0.95}\right)$ at this point, and maximal reaction temperature $\left(T_{\max }\right)$ for a data set with varied heat transfer parameters

\begin{tabular}{|c|c|c|c|}
\hline Dataset & $t_{0.95}[\mathrm{~min}]$ & $\bar{M}_{n, 0.95}\left[\mathrm{~kg} \mathrm{~mol}^{-1}\right]$ & $T_{\max }\left[{ }^{\circ} \mathrm{C}\right]$ \\
\hline \multicolumn{4}{|c|}{ Temperature of Thermo-Fluid } \\
\hline $60{ }^{\circ} \mathrm{C}$ & 7.5 & 92.70 & 71.82 \\
\hline $55^{\circ} \mathrm{C}$ & 9.7 & 92.54 & 67.31 \\
\hline $50{ }^{\circ} \mathrm{C}$ & 13.5 & 92.41 & 62.67 \\
\hline $40{ }^{\circ} \mathrm{C}$ & 40.4 & 92.61 & 60.00 \\
\hline \multicolumn{4}{|c|}{ Volume Flow Rate of Thermo-Fluid } \\
\hline $5 \mathrm{~L} \mathrm{~min}^{-1}$ & 7.2 & 92.54 & 72.26 \\
\hline $10 \mathrm{~L} \mathrm{~min}^{-1}$ & 7.5 & 92.70 & 71.82 \\
\hline $20 \mathrm{~L} \mathrm{~min}^{-1}$ & 7.5 & 92.6 & 71.55 \\
\hline $40 \mathrm{~L} \min ^{-1}$ & 7.6 & 92.55 & 71.39 \\
\hline $100 \mathrm{~L} \mathrm{~min}^{-1}$ & 7.6 & 92.49 & 71.28 \\
\hline \multicolumn{4}{|c|}{ Stirrer Speed } \\
\hline $150 \min ^{-1}$ & 7.0 & 92.47 & 73.05 \\
\hline $200 \min ^{-1}$ & 7.2 & 92.59 & 72.33 \\
\hline $250 \min ^{-1}$ & 7.5 & 92.70 & 71.82 \\
\hline $300 \min ^{-1}$ & 7.5 & 92.52 & 71.42 \\
\hline $350 \min ^{-1}$ & 7.7 & 92.67 & 71.10 \\
\hline \multicolumn{4}{|c|}{ Stirrer Type } \\
\hline Spiral Stirrer & 7.5 & 92.70 & 71.82 \\
\hline Paravisc Stirrer & 9.7 & 92.56 & 69.83 \\
\hline Anchor Stirrer & 13.7 & 92.44 & 70.88 \\
\hline Inclined Blade Stirrer & 40.44 & 92.63 & 74.70 \\
\hline
\end{tabular}




\section{Adapting the process parameter for the Scale-Up}

Adaption of some process parameters (Figure S3) in order to lower the increase of temperature.

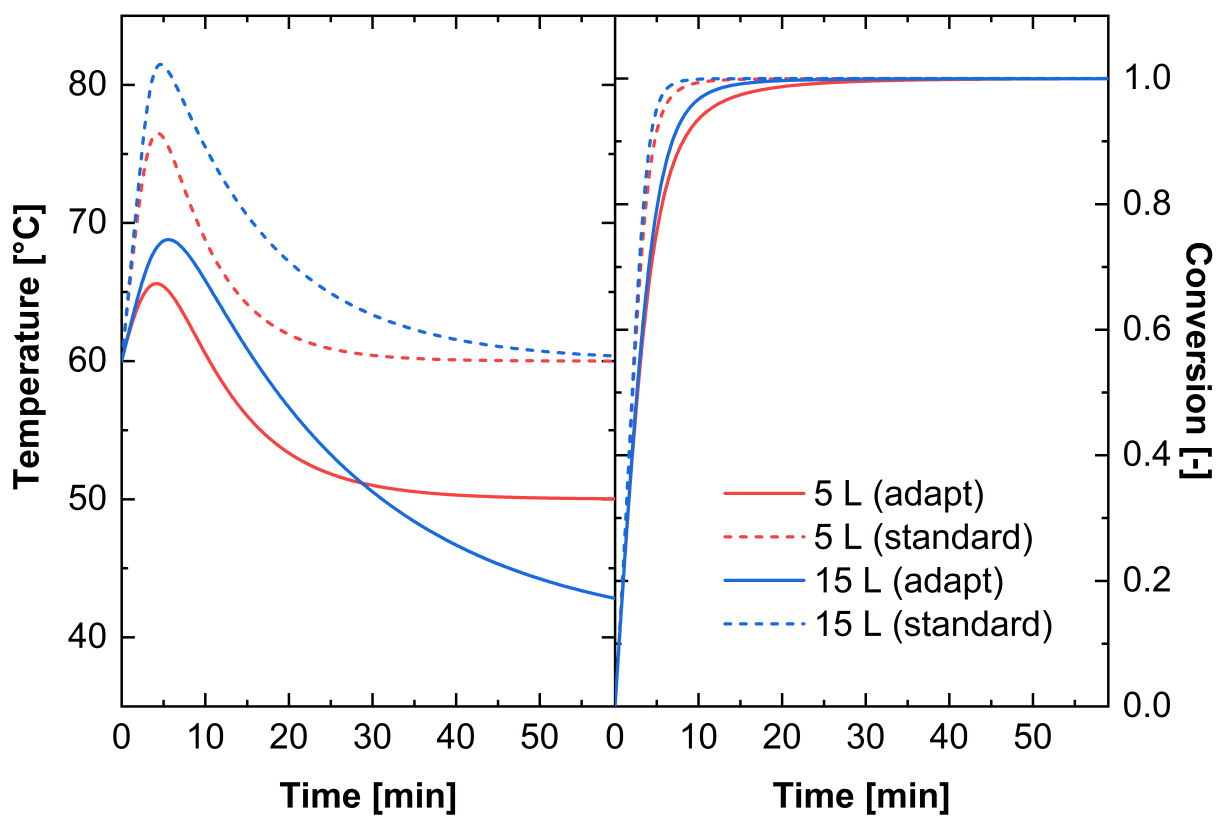

Figure S3: Reactions scaled-up to $5 \mathrm{~L}$ (red) and $15 \mathrm{~L}$ (blue) carried out with the standard process parameter (dashed lines) and adapted process parameters (straight lines). 


\section{References}

(1) VDI-wärmeatlas; Springer Berlin Heidelberg, 2006; p 1136-1162.

(2) Steube, M.; Johann, T.; Plank, M.; Tjaberings, S.; Gröschel, A. H.; Gallei, M.; Frey, H.; Müller, A. H. E. Kinetics of Anionic Living Copolymerization of Isoprene and Styrene Using in Situ NIR Spectroscopy: Temperature Effects on Monomer Sequence and Morphology. Macromolecules 2019, 52, 9299-9310.

(3) Malotherm XC Data Sheet. http://www.sasolgermany.de/fileadmin/images/ marlotherm/MARLOTHERM_XC_info_e_.pdf, Date accessed: 24.02.2021.

(4) Styrene Product Data Sheet. https://cameochemicals.noaa.gov/chris/STY.pdf, Date accessed: 24.02.2021.

(5) Cyclohexane Product Data Sheet. https://cameochemicals.noaa.gov/chris/CHX. pdf, Date accessed: 24.02.2021.

(6) Rodriguez-Guadarrama, L. Modeling of Anionic Polymerization of Isoprene in an Industrial Reactor. Macromolecular Reaction Engineering 2019, 13, 1-7.

(7) Isoprene Product Data Sheet. https://cameochemicals.noaa.gov/chris/IPR.pdf, Date accessed: 19.03.2021.

(8) Brandrup, J.; Immergut, E.; Grulke, E. Polymer Handbook; A Wiley-Interscience Publication; Wiley, 1999.

(9) Cui, J.; Ni, L.; Jiang, J.; Pan, Y.; Wu, H.; Chen, Q. Computational Fluid Dynamics Simulation of Thermal Runaway Reaction of Styrene Polymerization. Organic Process Research and Development 2019, 23, 389-396.

(10) Gaur, U.; Wunderlich, B. B.; Wunderlich, B. Heat Capacity and Other Thermodynamic Properties of Linear Macromolecules. VII. Other Carbon Backbone Polymers. Journal of Physical and Chemical Reference Data 1983, 12, 29-63. 
(11) Zhao, L.; Zhu, W.; Papadaki, M. I.; Mannan, M. S.; Akbulut, M. Probing into Styrene Polymerization Runaway Hazards: Effects of the Monomer Mass Fraction. ACS Omega 2019, 4, 8136-8145.

(12) Dreyer, R.; Martin, W.; Weber, U. v. Die Sättigungsdampfdrucke von Benzol, Toluol, Äthylbenzol, Styrol, Cumol and Brombenzol zwischen 10 und 760 Torr. Journal für Praktische Chemie 1955, 1, 324-328.

(13) Gubkov, A. N.; Fermor, N. A.; Smirnov, N. I. Vapor pressure of mono-poly systems. 1964; https : //webbook.nist.gov/cgi/cbook.cgi?ID=C78795\&\#38; Mask=4, Date accessed: 24.02.2021.

(14) Kerns, W. J.; Anthony, R. G.; Eubank, P. T. Volumetric Properties of Cyclohexane Vapor. 1974; https://webbook.nist.gov/cgi/cbook.cgi?ID=C110827\&\#38; Mask=4\#ref-23, Date accessed: 24.02.2021. 